\title{
Three-Phase Low-Frequency Commutation Inverter for Renewables
}

\author{
José Antenor Pomilio, Geomar M. Martins \\ School of Electrical and Computer Engineering \\ University of Campinas \\ C. P. 6101 \\ 13081-970 Campinas - Brazil \\ e-mail:Antenor@dsce.fee.unicamp.br
}

\author{
Simone Buso, Giorgio Spiazzi \\ Department of Electronics and Informatics \\ University of Padova \\ Via Gradenigo 6/a \\ 31131 Padova - Italy \\ e-mail: giorgio.spiazzi@dei.unipd.it
}

\begin{abstract}
The connection of distributed power sources with the utility grid generally needs an electronic power converter for processing the locally generated power and injecting current into the system. If the source provides a DC voltage, the converter must be able to produce a lowdistortion, high-power factor AC current. The same aspects related with the voltage and current distortion produced by non-linear loads can be considered for the injection of power into the grid. In the absence of a specific standard, this paper takes as a reference the limits for current harmonics given by the IEC61000-3-4 technical report. The justification for this approach is that, from the resulting line voltage degradation, there is no difference between injected and absorbed current. This paper presents a three-phase inverter using low-frequency commutation. An auxiliary circuit is added to the inverter topology in order to reduce the output voltage distortion, thus improving the current waveform. The main advantages of this approach are the minimization of the switching losses (i.e. high efficiency) and the elimination of the EMI (which avoids high-frequency filters necessary in high-frequency commutation inverters).
\end{abstract}

\section{INTRODUCTION}

The connection of distributed power sources with the utility grid generally needs an electronic power converter for processing the locally generated power and injecting current into the system. If the source provides a DC voltage, the converter must be able to produce a low-distortion, high-power factor AC current.

The same aspects related with the voltage and current distortion produced by non-linear loads can be considered for the injection of power into the grid. In the absence of a specific standard, this paper takes as a reference the limits for current harmonics given by the IEC 61000-3-4 technical report [1]. The justification for this approach is that, from the resulting line voltage degradation, there is no difference between injected and absorbed current. The recommendations proposed in [1] are applicable to low-voltage single and three-phase systems with input current greater than 16 A per phase. The harmonic current limits are a percentage of the fundamental component, measured at the rated power.

For low-power applications, like photovoltaic panels and small fuel cells, a single-phase inverter (DC-AC converter) can be used for connecting the alternative source with the grid [2]. But above a few $\mathrm{kW}$ it is more convenient to use three-phase inverters.
PWM converters can be used to produce any voltage or current waveforms. This modulation technique has been used for many applications, including the connection of DC sources to the grid [3].

The main advantage of PWM inverters is the possibility of producing any current waveform, as shown in Fig. 1. Nevertheless these converters present some drawbacks especially related with the EMI generation, due to the highfrequency commutation, and a relatively low efficiency, due to the power switches losses [4]. A low-pass filter is necessary to attenuate the high-frequency components due to the switching process.

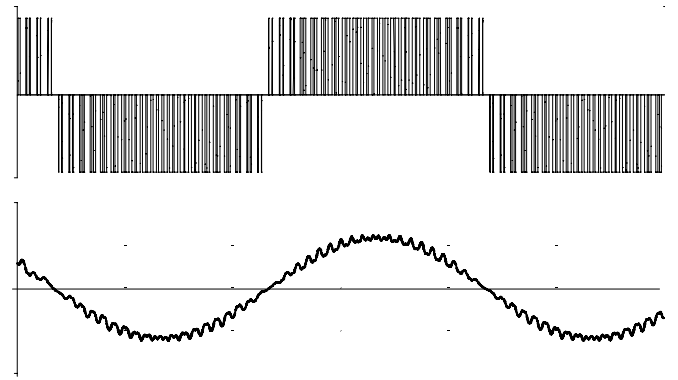

Fig. 1 - Three-level PWM waveform and filtered resulting voltage.

There are other converter topologies presented for grid interfaces applications [5], but they also use high-frequency commutation, thus EMI filters are still necessary if one is interested in injecting a low-distortion current into the line.

This paper presents a three-phase inverter using lowfrequency commutation. The converter is based on the lowfrequency commutation three-phase rectifier [6]. An auxiliary circuit is added to the inverter topology in order to reduce the output voltage distortion, thus improving the current waveform. The main advantages of this approach are the minimization of switching losses, which increases the converter efficiency, and the elimination of the EMI filter.

The circuit is conceived as an interface between DC sources and AC lines and does not present the capability of compensating local load current distortions.

A comparison among low and high frequency commutation rectifiers was presented in [7]. Most of the conclusions can be extended to DC-AC topologies. The most important aspects are that the switching losses ask for a high heat-sink volume and the limitation of the conducted EMI needs a huge filter. In both cases the consequence is the reduction of the overall converter power density. 
It is not possible, without a specific study, to conclude which converter would present the highest power density, but one should not previously discard the low frequency commutation alternative.

\section{THE PROPOSED TOPOLOGY}

Fig. 2 shows the proposed converter topology. The bridge switches are controlled so as to apply at the inverter terminals a voltage that results in a quasisinusoidal line current. Each bridge switch operates at the line frequency, while the auxiliary switches at twice this frequency, as shown in Fig. 3.

The fundamental component of the inverter voltage $\left(\mathrm{v}_{\text {inv1 }}\right)$ must be adjusted to produce the desired current through the output inductor.

The design procedure is oriented to select the minimum inductance value that simultaneously allows generating the rated power and complying with the current harmonic limits. The inductor voltage $\mathrm{v}_{\mathrm{L}}$ must lead by $90^{\circ}$ the respective line voltage to minimize the RMS line current, as shown in Fig. 4. This procedure maximizes the resulting power factor.

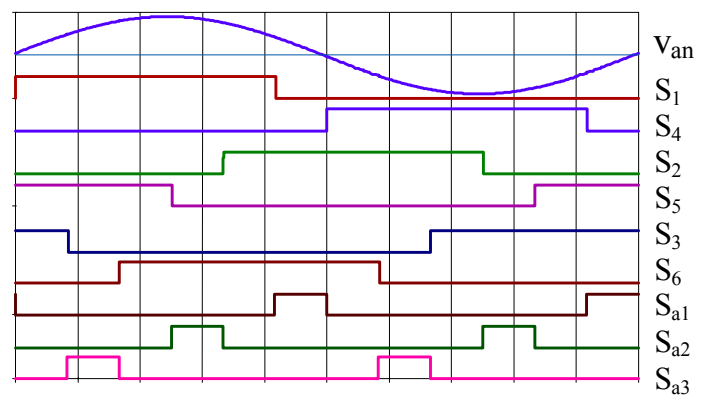

Fig. 3 - Typical switches command signals.

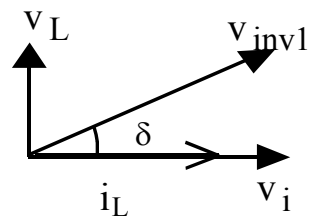

Fig. 4 - Phasorial representation of the voltages on phase $a$

Without the auxiliary circuit operation, the inverter lineto-line output voltage presents a three level waveform while the line-to-neutral voltage has four levels, both waveforms with sharp edges, as shown in Fig. 5. The current harmonics will depend on the voltage components of the line-to-neutral voltage, divided by the respective reactance.

The effect of the auxiliary circuit, as shown in Fig. 6, is to smooth the edges, thus reducing the harmonic components of the inverter output voltage and allowing reducing the inductance needed to comply with the standard.

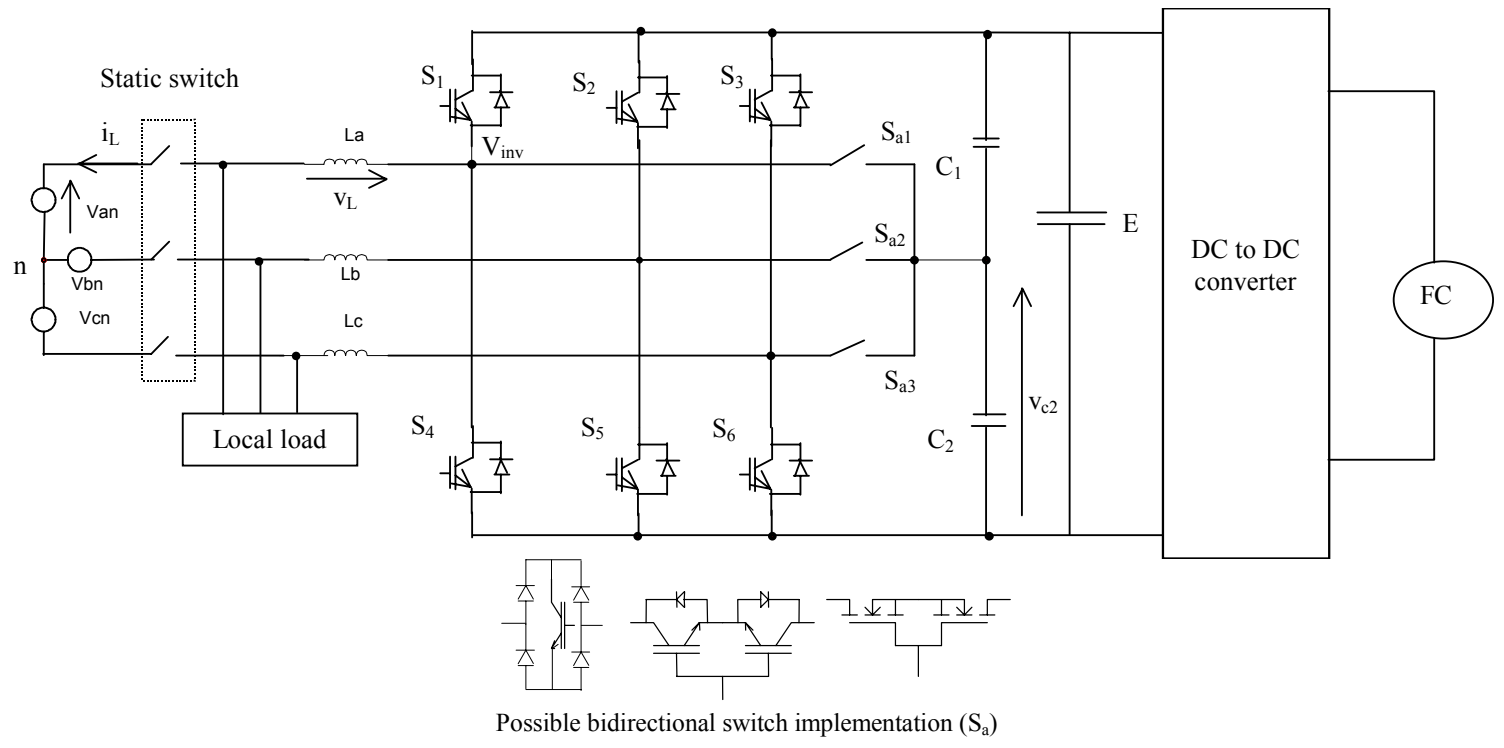

Fig. 2 - Three-phase inverter and the bi-directional switch. 


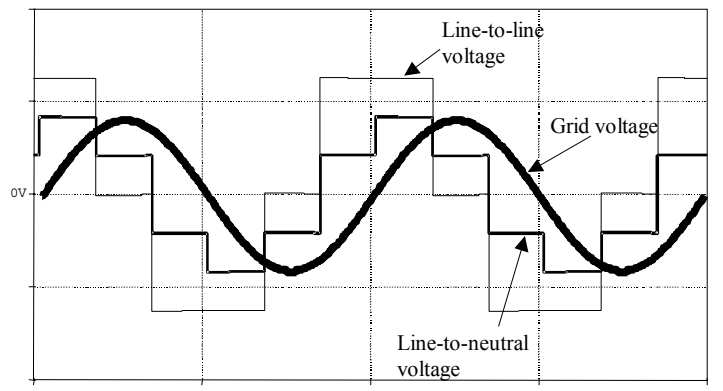

Fig. 5 - Inverter output voltages, without the auxiliary circuit.

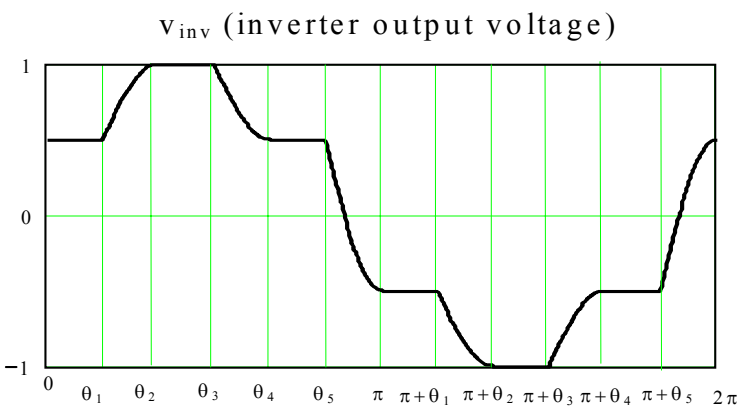

Fig. 6 - Inverter output voltages with the auxiliary circuit.

The inductor voltage is the difference between the line and the inverter voltage:

$\mathrm{v}_{\mathrm{L}}(\theta)=\mathrm{v}_{\text {inv }}(\theta)-\mathrm{V}_{\mathrm{p}} \sin \theta$

The current injected into the grid is:

$\mathrm{i}_{\mathrm{L}}=\frac{1}{\omega_{\mathrm{i}} \cdot \mathrm{L}} \int \mathrm{v}_{\mathrm{L}}(\theta) \mathrm{d} \theta$

The peak-to-peak capacitor voltage variation is $\mathrm{V}_{\mathrm{r}}$. This value can vary from $\mathrm{E}$ (for a complete excursion) to 0 (for a infinite capacitance or null resonant interval). In the next analysis the resonant interval is approximated as a sinusoidal variation. In fact it is not, due to the harmonic currents, but as will be shown, the results are quite similar.

For $0 \leq \theta \leq \theta_{1}$

$\mathrm{v}_{\text {inv }}=\frac{\mathrm{E}}{3}$

$\mathrm{i}_{\mathrm{L}}=\frac{1}{\omega_{\mathrm{i}} \mathrm{L}}\left[\frac{\mathrm{E} \theta}{3}+\mathrm{V}_{\mathrm{p}}(\cos (\theta)-1)\right]+\mathrm{i}_{\mathrm{L}}(0)$

For $\theta_{1} \leq \theta \leq \theta_{2}$

$\mathrm{v}_{\text {inv }}=\frac{\mathrm{E}}{2}-\frac{\mathrm{V}_{\mathrm{r}}}{6}+\frac{\mathrm{V}_{\mathrm{r}}}{3} \sin \left[\alpha\left(\theta-\theta_{1}\right)\right]$

$\left.\mathrm{i}_{\mathrm{L}}=\mathrm{i}_{\mathrm{L}}\left(\theta_{1}\right)+\frac{1}{\omega_{\mathrm{i}} \mathrm{L}}\left\{\begin{array}{l}{\left[\left(\frac{\mathrm{E}}{2}-\frac{\mathrm{V}_{\mathrm{r}}}{6}\right)\left(\theta-\theta_{1}\right)\right.} \\ +\mathrm{V}_{\mathrm{p}}\left(\cos (\theta)-\cos \left(\theta_{1}\right)\right.\end{array}\right]\right\}$

For $\theta_{2} \leq \theta \leq \theta_{3}$

$$
\begin{aligned}
& \mathrm{v}_{\text {inv }}=\frac{2 \mathrm{E}}{3} \\
& \mathrm{i}_{\mathrm{L}}=\frac{1}{\omega_{\mathrm{i}} \mathrm{L}}\left[\frac{2 \mathrm{E}\left(\theta-\theta_{2}\right)}{3}+\mathrm{V}_{\mathrm{p}}\left(\cos (\theta)-\cos \left(\theta_{2}\right)\right]+\mathrm{i}_{\mathrm{L}}\left(\theta_{2}\right)\right.
\end{aligned}
$$

For $\theta_{3} \leq \theta \leq \theta_{4}$

$$
\begin{aligned}
& \mathrm{v}_{\text {inv }}=\frac{\mathrm{E}}{2}+\frac{\mathrm{V}_{\mathrm{r}}}{6}-\frac{\mathrm{V}_{\mathrm{r}}}{3} \sin \left[\alpha\left(\theta-\theta_{3}\right)\right] \\
& \mathrm{i}_{\mathrm{L}}=\mathrm{i}_{\mathrm{L}}\left(\theta_{3}\right)+\frac{1}{\omega_{\mathrm{i}} \mathrm{L}}\left\{\begin{array}{l}
{\left[\left(\frac{\mathrm{E}}{2}+\frac{\mathrm{V}_{\mathrm{r}}}{6}\right)\left(\theta-\theta_{3}\right)+\mathrm{V}_{\mathrm{p}}\left(\cos (\theta)-\cos \left(\theta_{3}\right)\right]\right.} \\
+\frac{\mathrm{V}_{\mathrm{r}}}{3 \alpha}\left\{\cos \left[\alpha\left(\theta-\theta_{3}\right)\right]-1\right\}
\end{array}\right\}
\end{aligned}
$$

For $\theta_{4} \leq \theta \leq \theta_{5}$

$\mathrm{v}_{\text {inv }}=\frac{\mathrm{E}}{3}$

$\mathrm{i}_{\mathrm{L}}=\frac{1}{\omega_{\mathrm{i}} \mathrm{L}}\left[\frac{\mathrm{E}\left(\theta-\theta_{4}\right)}{3}+\mathrm{V}_{\mathrm{p}}\left(\cos (\theta)-\cos \left(\theta_{4}\right)\right]+\mathrm{i}_{\mathrm{L}}\left(\theta_{4}\right)\right.$

For $\theta_{5} \leq \theta \leq \pi$

$\mathrm{v}_{\mathrm{inv}}=\frac{\mathrm{V}_{\mathrm{r}}}{3}\left\{1-2 \sin \left[\alpha\left(\theta-\theta_{5}\right)\right]\right\}$

$\mathrm{i}_{\mathrm{L}}=\mathrm{i}_{\mathrm{L}}\left(\theta_{5}\right)+\frac{1}{\omega_{\mathrm{i}} \mathrm{L}}\left\{\begin{array}{l}\frac{\mathrm{V}_{\mathrm{r}}}{3}\left(\theta-\theta_{5}\right)+\mathrm{V}_{\mathrm{p}}\left(\cos (\theta)-\cos \left(\theta_{5}\right)\right] \\ +\frac{2 \mathrm{~V}_{\mathrm{r}}}{3 \alpha}\left\{\cos \left[\alpha\left(\theta-\theta_{5}\right)\right]-1\right\}\end{array}\right\}$

During the negative semi-cycle:

For $\pi \leq \theta \leq \pi+\theta_{1}$

$\mathrm{v}_{\text {inv }}=-\frac{\mathrm{E}}{3}$

$\mathrm{i}_{\mathrm{L}}=\frac{1}{\omega_{\mathrm{i}} \mathrm{L}}\left[-\frac{\mathrm{E}(\theta-\pi)}{3}+\mathrm{V}_{\mathrm{p}}(\cos (\theta)+1)\right]+\mathrm{i}_{\mathrm{L}}(\pi)$

For $\pi+\theta_{1} \leq \theta \leq \pi+\theta_{2}$

$\mathrm{v}_{\text {inv }}=-\frac{\mathrm{E}}{2}+\frac{\mathrm{V}_{\mathrm{r}}}{6}-\frac{\mathrm{V}_{\mathrm{r}}}{3} \sin \left[\alpha\left(\theta-\theta_{1}-\pi\right)\right]$

$i_{L}=i_{L}\left(\theta_{1}+\pi\right)+\frac{1}{\omega_{i} L}\left\{\begin{array}{l}{\left[\left(-\frac{E}{2}+\frac{V_{r}}{6}\right)\left(\theta-\theta_{1}-\pi\right)+V_{p}\left(\cos (\theta)-\cos \left(\theta_{1}+\pi\right)\right]\right.} \\ +\frac{V_{r}}{3 \alpha}\left\{\cos \left[\alpha\left(\theta-\theta_{1}-\pi\right)\right]-1\right\}\end{array}\right\}$

For $\pi+\theta_{2} \leq \theta \leq \pi+\theta_{3}$

$\mathrm{v}_{\text {inv }}=-\frac{2 \mathrm{E}}{3}$

$\mathrm{i}_{\mathrm{L}}=\frac{1}{\omega_{\mathrm{i}} \mathrm{L}}\left[\begin{array}{l}-\frac{2 \mathrm{E}\left(\theta-\theta_{2}-\pi\right)}{3} \\ +\mathrm{V}_{\mathrm{p}}\left(\cos (\theta)-\cos \left(\theta_{2}+\pi\right)\right.\end{array}\right]+\mathrm{i}_{\mathrm{L}}\left(\theta_{2}+\pi\right)$

For $\pi+\theta_{3} \leq \theta \leq \pi+\theta_{4}$

$\mathrm{v}_{\text {inv }}=-\frac{\mathrm{E}}{2}-\frac{\mathrm{V}_{\mathrm{r}}}{6}+\frac{\mathrm{V}_{\mathrm{r}}}{3} \sin \left[\alpha\left(\theta-\theta_{3}-\pi\right)\right]$

$\mathrm{i}_{\mathrm{L}}=\mathrm{i}_{\mathrm{L}}\left(\theta_{3}+\pi\right)+\frac{1}{\omega_{\mathrm{i}} \mathrm{L}}\left\{\begin{array}{l}\left(-\frac{\mathrm{E}}{2}-\frac{\mathrm{V}_{\mathrm{r}}}{6}\right)\left(\theta-\theta_{3}-\pi\right) \\ +\mathrm{V}_{\mathrm{p}}\left(\cos (\theta)-\cos \left(\theta_{3}+\pi\right)\right. \\ -\frac{\mathrm{V}_{\mathrm{r}}}{3 \alpha}\left\{\cos \left[\alpha\left(\theta-\theta_{3}-\pi\right)\right]-1\right\}\end{array}\right\}$

For $\pi+\theta_{4} \leq \theta \leq \pi+\theta_{5}$

$\mathrm{v}_{\text {inv }}=-\frac{\mathrm{E}}{3}$ 


$$
\mathrm{i}_{\mathrm{L}}=\frac{1}{\omega_{\mathrm{i}} \mathrm{L}}\left[-\frac{\mathrm{E}\left(\theta-\theta_{4}-\pi\right)}{3}+\mathrm{V}_{\mathrm{p}}\left(\cos (\theta)-\cos \left(\theta_{4}+\pi\right)\right]+\mathrm{i}_{\mathrm{L}}\left(\theta_{4}+\pi\right)\right.
$$

$$
\begin{aligned}
& \text { For } \pi+\theta_{5} \leq \theta \leq 2 \pi \\
& \mathrm{v}_{\text {inv }}=-\frac{\mathrm{V}_{\mathrm{r}}}{3}\left\{1-2 \sin \left[\alpha\left(\theta-\theta_{5}-\pi\right)\right]\right\} \\
& \mathrm{i}_{\mathrm{L}}=\frac{1}{\omega_{\mathrm{i}} \mathrm{L}}\left\{\begin{array}{l}
-\frac{\mathrm{V}_{\mathrm{r}}}{3}\left(\theta-\theta_{5}-\pi\right) \\
+\mathrm{V}_{\mathrm{p}}\left(\cos (\theta)-\cos \left(\theta_{5}+\pi\right)\right) \\
-\frac{2 \mathrm{~V}_{\mathrm{r}}}{3 \alpha}\left\{\cos \left[\alpha\left(\theta-\theta_{5}-\pi\right)\right]-1\right\}
\end{array}\right\}+\mathrm{i}_{\mathrm{L}}\left(\theta_{5}+\pi\right)
\end{aligned}
$$

\section{DESIGN PROCEDURE}

For a given maximum current, associated with the rated power, and in order to minimize the input inductance, it is interesting to reduce the phase-shift $\delta$. However, while the fundamental component of the current depends on the difference between the grid and the inverter voltages, the harmonics depend only on the inverter waveform.

Theoretically, considering only the fundamental component, the input inductance could tend to zero. In such a situation the harmonics would tend to infinity!

Fig. 7 shows the necessary inductance for each harmonic component, as a function of the resonant interval duration expressed in degrees. Notice that typically, for a wider resonant interval, the necessary inductance reduces, due to the reduction of the harmonic components. For the fundamental component the rated current is considered, while for the harmonics the limits are given by [1].

The best solution is the minimum inductance that allows injecting the nominal current while guaranteeing an acceptable harmonic content.

In Fig 7, for a DC voltage of $305 \mathrm{~V}$ and a rated power of $10 \mathrm{~kW}$, selecting the inductance determined by the fundamental component the harmonics will comply with the limitations for any resonant interval.

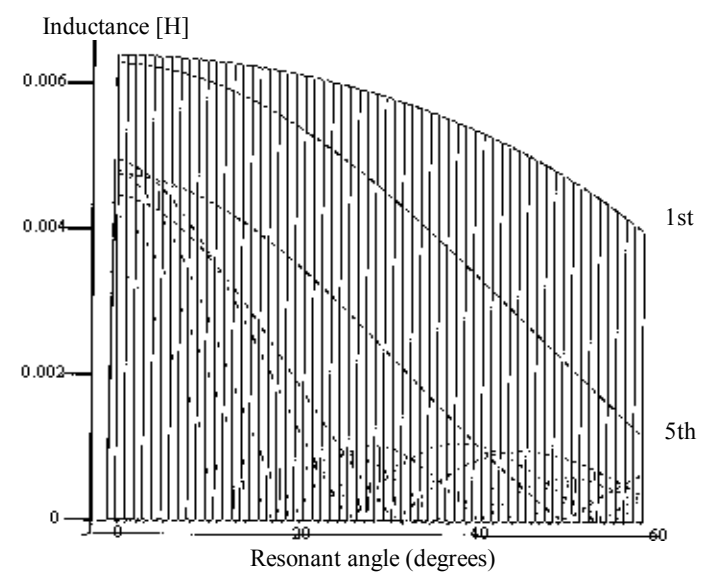

Fig. 7 Minimum inductance for compliance with [1].
The selected inductance value will be determined by the resonant angle that results in unitary displacement factor (DF).

Through numerical simulations it is possible to determine the relationship between the resonant angle, $\theta_{\mathrm{r}}$, and the angle $\delta$ (that results $\mathrm{DF}=1$ ), and the RMS value of the inverter voltage fundamental component. As can be seen, the $\mathrm{K}$ factor is almost constant all over the resonant angle range and its average value is $3.483 \mathrm{mV}^{-1}$.

$$
\begin{aligned}
& \theta_{\mathrm{r}}=1.5 \cdot \delta \\
& \mathrm{V}_{\text {inv1 }}=\mathrm{E} \cdot \mathrm{V}_{\mathrm{i}} \cdot \mathrm{K}
\end{aligned}
$$

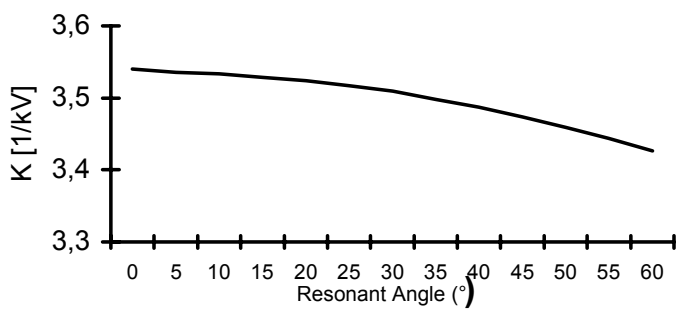

Fig. 8 - Parameter K for different resonant angles.

The input data are: line voltage, $\mathrm{Vi}$, and rated power (per phase), $\mathrm{P}_{\max }$. For $\mathrm{P}_{\max }$ the capacitor voltage excursion in complete $\left(\mathrm{V}_{\mathrm{r}}=\mathrm{E}\right)$.

1) Based on numerical calculus, find the minimum DC link voltage, $\mathrm{E}$, for which the inductance associated with the fundamental component are always higher than the values calculated for the harmonics, as done in fig. 7.

2) Estimate the inverter voltage fundamental component: $\mathrm{V}_{\text {inv1 }}=\mathrm{E} \cdot \mathrm{V}_{\mathrm{i}} \cdot \mathrm{K}$

3) Known $\mathrm{Vi}$ and $\mathrm{V}_{\text {inv1 }}$, determine $\mathrm{V}_{\mathrm{L}}$ e $\delta$

$\delta=\operatorname{acos}\left(\frac{\mathrm{V}_{\mathrm{i}}}{\mathrm{V}_{\mathrm{inv1}}}\right) \quad \mathrm{V}_{\mathrm{L}}=\mathrm{V}_{\mathrm{i}} \cdot \tan (\delta)$

4) Determine $\theta_{\mathrm{r}}$.

5) Determine L according to Fig. 7 (specific for each set of parameters).

6) Numerically, determine the average current during the interval $\theta_{5}$ to $\pi(\mathrm{Im})$ and evaluate the capacitor value:

$\mathrm{C}=\frac{\operatorname{Im} \cdot \theta_{\mathrm{r}}}{2 \cdot \omega_{\mathrm{i}} \cdot \mathrm{E}}$

\section{SiMULATION RESULTS}

Fig. 9 shows the current waveform and the respective spectrum, at rated power. In this simulation, for a $127 / 220 \mathrm{~V}$ grid, the component values are: $5.9 \mathrm{mH}$ input inductance, $36 \mu \mathrm{F}$ resonant capacitance. The rated power injected into the grid is $10 \mathrm{~kW}$, corresponding to $26 \mathrm{~A}_{\mathrm{RMS}}$. The DC voltage is $305 \mathrm{~V}$. The Total Harmonic Distortion (THD) of the current 
is $10 \%$ and the harmonics comply with the recommended limitations.
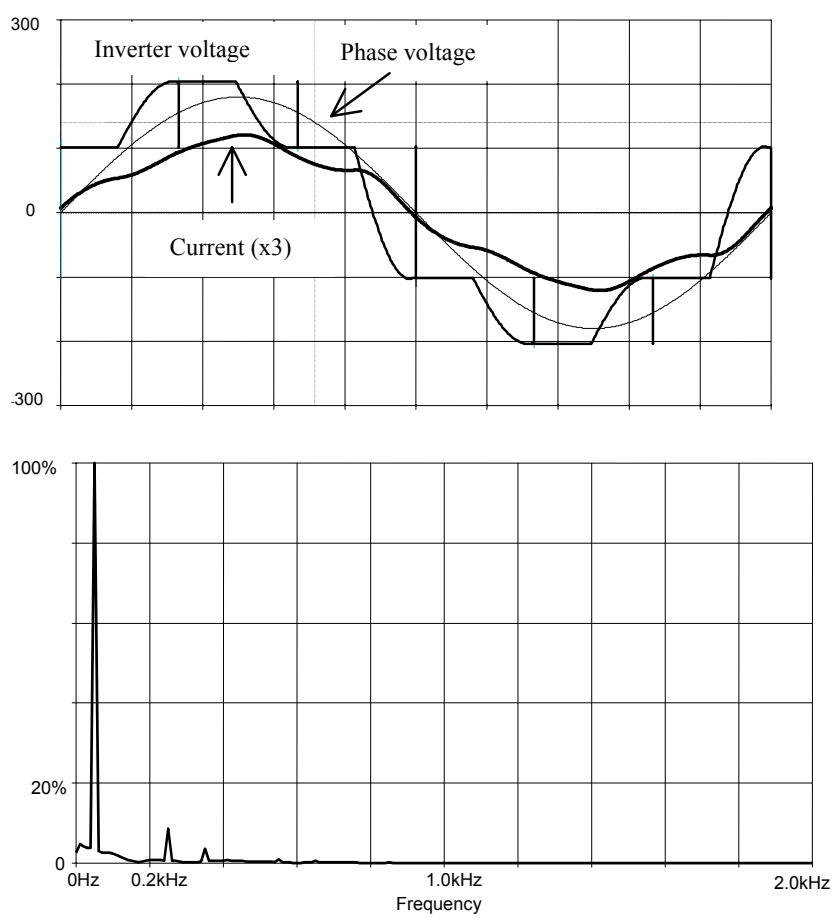

Fig. 9 - Voltage and current waveforms and normalized current spectrum.

For reduced power generation there are different possibilities: reducing the DC voltage, adjusting the phase shift between the grid voltage and the inverter voltage, modulating the switches' duty-cycle or even a combination of these.

Another situation that must be considered is the islanding. In this case the line must be disconnected and the inverter will supply the local load. It is necessary to ensure a local synchronism and stabilize the $\mathrm{AC}$ voltage. Using a DC voltage next to the line peak voltage, and maintaining the switching pattern, the resulting waveform will be the same as shown in Fig. 9. The voltage THD is $22 \%$.

A lower distortion can be obtained by adding a capacitive filter at the output, as shown in Fig. 10. The voltage waveform will be improved for a dominantly resistive load. The THD is $9.5 \%$, the peak voltage is maintained as compared with the nominal line-to-phase voltage. For non-linear loads (like rectifiers), the output filter resonance can degrade the waveform. When the line voltage returns, it is necessary to guarantee synchronization before the reconnection.

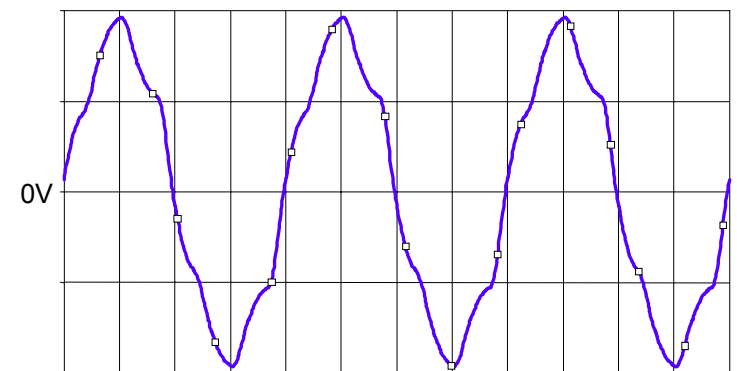

Fig. 10 - Output voltage waveform for islanding condition.

\section{EXPERIMENTAL RESULTS}

A preliminary prototype, operating without the auxiliary circuit has been tested in order to verify the circuit behavior and the design procedure. The main waveforms are shown in Fig. 11. The DC voltage is $100 \mathrm{~V}$, the AC line voltage is $55 \mathrm{~V}_{\mathrm{RMS}}$, and the inverter is connected with the line through a three-phase transformer bank.

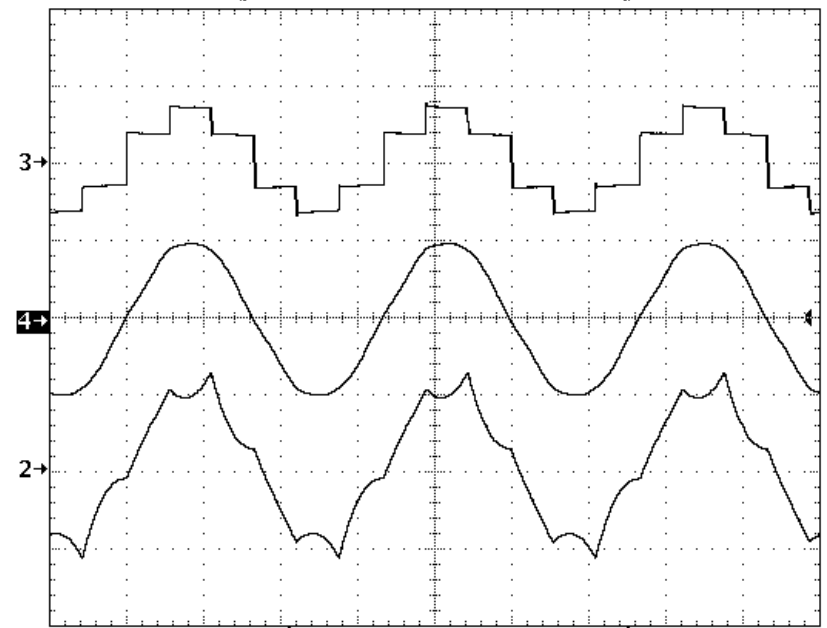

Fig. 11 - Inverter voltage (100 V/div.), Line voltage (75 $\mathrm{V} /$ div.) and line current (5 A/div.). Horiz. $5 \mathrm{~ms} / \mathrm{div}$.

\section{CONCLUSIONS}

The proposed three-phase, low-frequency commutation inverter presents some interesting characteristics if one is looking for low-cost, good-quality inverters suitable for distributed generation systems, based on DC primary sources, connected with the utility grid. Taking as quality parameter, the current distortion limits established by international standards, the current injected into the grid by the topology presents low distortion and high-power factor. As the circuit operates at the line frequency, EMI filters are not necessary, and the switching losses can be neglected, thus reducing the heatsink area. The design procedure minimizes the inductance and the DC voltage value. If it would be necessary to control the injected power, it could be done controlling the auxiliary switches conduction time. 


\section{ACKNOWLEDGEMENT}

Authors would like to ackowledge the Fundação de Amparo à Pesquisa do Estado de São Paulo - FAPESP and Fundação CAPES by supporting of this project.

\section{REFERENCES}

[1] IEC 61000-3-4, First Edition 1998-10, Commission Electrotechnique Internationale, 3, rue de Varembé, Genève, Switzerland.

[2] G. M. Martins, J. A. Pomilio, S. Buso: "A SinglePhase Low-frequency Commutation Inverter for Renewables", IEEE IECON, Denver, USA, Nov/Dec 2001.

[3] G. A. O'Sullivan, "Fuel Cell Inverter for Utility Applications", CD-ROM of the IEEE Power Electronics Specialists Conference, Galway, Ireland, June 2000.

[4] U.S. Departament of Energy et al., "2001 Future Energy Challenge", Homepage URL: HYPERLINK http://energy.uiuc.edu/energychallenge/main.html/Fu tureEnergyChallenge

[5] G. Ledwich and P. Wang, "Simple Grid Interfaces for Renewables", International Journal of Renewable Energy Engineering, vol. 1, No. 2, August 1999, pp. 50-55.

[6] J. A. G. Marafão, J. A. Pomilio, G. Spiazzi, "Improved three-phase high-quality rectifier with line-commutated switches", CD-ROM of the IEEE Power Electronics Specialists Conference, Vancouver, Canada, June 2001.

[7] J. A. Pomilio, G. Spiazzi, S. Buso, "Comparison among High-Frequency and Line-Frequency Commutated rectifiers Complying with IEC 610003-2 Standards", CD-ROM of the IEEE IAS Conference, Rome, Italy, Oct. 2000.

[8] EN61000-3-2, Limits for harmonic current emissions (equipment input current up to and including 16A per phase) First Edition 1995, European Committee for Electrotechnical Standardization, Brussels, Belgique.

\section{APPENDIX}

The technical report IEC 61000-3-4 stablishes "Limitation of emission of harmonic currents in lowvoltage power supply systems for equipment with rated current greater than 16 A per phase”.

The limits shown in Table I are those called "stage 1: current emission values for simplified connection of equipment $\left(\mathrm{S}_{\text {equ }} \leq \mathrm{S}_{\mathrm{sc}} / 33\right)$ ", reported in Table I. As we can see, each harmonic current limit is specified as a function of the rated fundamental current (up to the $40^{\text {th }}$ harmonic). This fact allows to analyze the converter input current normalized to a unity fundamental current, so as to obtain results that are independent of the input power.

If the input current is lower than $16 \mathrm{~A}$, one should consider the constant limits given by EN 61000-3-2 [8], class A, shown in Table II.

Table I - Limits of technical report IEC 61000-3-4: "Stage1: current emission values for simplified connection of equipment $\left(\mathrm{S}_{\text {equ }} \leq \mathrm{S}_{\mathrm{sc}} / 33\right) "$

\begin{tabular}{|c|c|}
\hline $\begin{array}{l}\text { Harmonic number } \\
\mathrm{n}\end{array}$ & $\begin{array}{l}\text { Admissible harmonic } \\
\text { current } \mathbf{I}_{\mathbf{n}} / \mathbf{I}_{1}{ }^{*} \%\end{array}$ \\
\hline 3 & 21.6 \\
\hline 5 & 10.7 \\
\hline 7 & 7.2 \\
\hline 9 & 3.8 \\
\hline 11 & 3.1 \\
\hline 13 & 2 \\
\hline 15 & 0.7 \\
\hline 17 & 1.2 \\
\hline 19 & 1.1 \\
\hline 21 & $\leq 0.6$ \\
\hline 23 & 0.9 \\
\hline 25 & 0.8 \\
\hline 27 & $\leq 0.6$ \\
\hline 29 & 0.7 \\
\hline 31 & 0.7 \\
\hline$\geq 33$ & $\leq 0.6$ \\
\hline Even & $\leq 8 / \mathrm{n}$ or $\leq 0.6$ \\
\hline
\end{tabular}

Table II - EN 61000-3-2 Limits for harmonic current emissions (equipment input current up to and including 16A

\begin{tabular}{|c|c|}
\hline $\begin{array}{c}\text { Harmonic number } \\
\mathrm{n}\end{array}$ & $\begin{array}{c}\text { Class A limits } \\
{\left[\mathrm{A}_{\text {rms }}\right]}\end{array}$ \\
\hline 3 & 2.300 \\
\hline 5 & 1.140 \\
\hline 7 & 0.770 \\
\hline 9 & 0.400 \\
\hline 11 & 0.330 \\
\hline 13 & 0.210 \\
\hline $15 \leq \mathrm{n}<39$ & $2.25 / \mathrm{n}$ \\
\hline 2 & 1.08 \\
\hline 4 & 0.43 \\
\hline 6 & 0.3 \\
\hline $8 \leq \mathrm{n}<40$ & $1.84 / \mathrm{n}$ \\
\hline
\end{tabular}

